Case-Commentary

\title{
Hysterectomy in the mentally disabled female: An ethical dilemma.
}

Anna Rana

Aga Khan School of Nursing and Midwifery, Karachi, Pakistan

Doi: 10.29052/IJEHSR.v8.i3.2020.112-116

\section{Corresponding Author Email:}

annarana915@gmail.com

Received 02/05/2020

Accepted 07/08/2020

First Published 01/09/2020

(c) (7)

(C) The Author(s). 2020 Open Access This article is distributed under the terms of the Creative Commons Attribution 4.0 International License (http://creativecommons.org/licenses/by/4.0/)

\section{OPEN ACCESS}

\section{Abstract}

The establishment of menstrual hygiene, specifically among the mentally disabled females, is one of the most critical concerns posing challenges for the individual, family and caretaker. Although the performance of hysterectomy among females with intellectual disabilities (ID) is now trending, but it has given rise to many ethical questions. Therefore, the study aimed to address the ethical dilemmas associated with hysterectomy among ID females, taking reference from a case of 19-year-old female, unable to practice menstrual hygiene.

\section{Keywords}

Hysterectomy, Mentally Disabled, Intellectual disability (ID), Non-Maleficence, Consequentialism, Right Based Ethics, Paternalism, Duty Based Ethics.

Check for updates 


\section{Introduction}

Intellectual Disability (ID) is characterized by difficulties in both intellectual learning abilities including understanding, learning, and remembering new things, and in adaptive behaviors ${ }^{1}$. It is estimated that globally around 300 million women and girls are living with an intellectual, mental, sensory, and physical disability ${ }^{1}$, making three-fourths of the overall disabled people in the low and middle-income countries ${ }^{1}$. Menstruation needs to be hygienically managed, ID individuals are mostly unable to practice menstrual hygiene; therefore, taking care of such individuals' poses challenges for the family or caregivers. It is evident that such females display a variety of behavioural inabilities and irregular physical symptoms during, before and after menstruation?

\section{Case Presentation}

Author experienced a situation in which, a 19-yearold female was brought to the gynecologist by her mother for hysterectomy. Upon inquiry, it was found that she was mentally disabled and was unable to practice menstrual hygiene. The patient's mother, who was excessively burdened by menstruation and hygiene issues of the patient, informed that due to her age and arthritic problems, she was no longer in state of helping her daughter with the menstruation associated chores each month. Thus, the mother wanted to go for hysterectomy for the patient, which invokes several ethical concerns considering the patients mental instability and might be a violation of individual rights.

\section{Parental Perspective and decision making}

There has been a long debate over the familial decision making in favour or against hysterectomy for disabled females. Some studies support the idea that parental rights extend to the hysterectomy demand for their daughter with ID due to issues with her menstrual hygiene and other related concerns ${ }^{3}$. While, others stand in support of individual's rights, limiting the parental decision making ${ }^{4,5}$. One of the significant and evident reasons behind the mother's decision for opting hysterectomy for her teenage girl was the older age of the mother herself as she was to take care of her mentally disabled daughter. Moreover, she might also be afraid of the societal pressures and values that do not allow her father or brother (potential care provider) to give personal care to the daughter or sister. Moreover, the children with mental disabilities are more vulnerable and easy targets for sexual exploitation and abuse, the risk is $39-60 \%$ for females and $16-30 \%$ for males ${ }^{6}$. Furthermore, the families also fear the development of sexual desires, perception and attitude among their children with ID patients ${ }^{7}$.

The local Pakistani culture and societal trends pressurize the families leaving no other options than to go for hysterectomy. Locally, the abuse and exploitation of such females are very common. So, caregivers and families of the sufferers feel overburdened and helpless due to a lack of social and emotional support ${ }^{8}$. Therefore, parents of intellectually disabled females make such decisions without considering any other alternative solution? ${ }^{9}$.

\section{Case Analysis}

According to Edward De Bono, "An expert is someone who has succeeded in making decisions and judgments simpler through knowing what to pay attention to and what to ignore"10. While studying the above-mentioned case, it was found that the decision making under these situations is very critical as these issues are least considered and discussed in our society. Therefore, it is essential to make a justified and reasonable decision by analyzing it under the light of ethical principles.

\section{Ethical Principles upon hysterectomy \& menstrual hygiene in women with ID}

Non-maleficence versus Consequentialism

Non-maleficence "do no harm" is prima facia11; thus, sufferers should not be harmed by any decision of either the family or caretakers. Surgery is the undue harm to the individual and may develop complications ${ }^{11}$. Instead of giving harm, 
other alternative options, including training and guidance for the sufferers,' and their primary care providers regarding menstrual hygiene, should be considered. However, ID individuals have learning disabilities so, they cannot learn menstrual hygiene and are prone to reproductive tract infections. Ultimately their mothers or primary caretakers are the ones who suffer. Moreover, siblings of the sufferers could be affected negatively, and they might feel stressed by such strenuous circumstances every month, specifically those under pubertal age. The question here is how the family burden will be justified in these situations?

Contrary to this, if we look upon the consequentialism theory, which considers the consequences of actions ${ }^{11}$. Performing hysterectomy for ID individuals promotes good for themselves, mothers and other family members. Individual's discomfort, irritation, restlessness, disturbed sleep and aggressiveness associated with menstruation will subside ${ }^{11}$. Together with that, the mother's or care taker's exertion related to the sufferer's menstruation will also subside. Other family members who may be affected by the aggressive behaviour of the sufferer and feel embarrassed in front of each other related to menstruation will be abate. Overall, it will reduce the family stress and financial burden.

\section{Right Based \& Duty Based Ethics versus Paternalism}

According to right-based ethics, every person has its rights ${ }^{11,12}$. Despite being disabled as a female, it is her right to preserve her reproductive organs, and others should respect it. The right of the sufferer cannot be superseded for mother/caregiver interest ${ }^{13}$. In the present case performing surgical procedure lead to violation of human right. However, parent's right over their child having ID can extend to hysterectomy for menstrual hygiene. But the right of a female with ID cannot be violated for mother interest that she cannot take care of her daughter during mensuration days. Moreover, according to dutybased ethics theory, a mother has to take care of her daughter even in her mensuration days ${ }^{12}$.
Contrary to this, according to the paternalistic approach, interruption in a person's right, to do good without his/her will can be overridden ${ }^{14}$. In this case, the mother is taking a paternalistic approach to promoting good for her daughter. The mother's concern is not to violate her daughter's rights but to protect her dignity and comfort her, taking away the menstrual distress ${ }^{3}$. Moreover, the individuals with ID are not usually capable or eligible to marry and settle, hence supporting mother's decision, as her daughter won't be getting married and won't have to deal with pregnancy issues. But this decision won't justify the reproductive rights of the sufferers, and factually it is female's right to retain her reproductive organ regardless of ID.

\section{Global \& Islamic Perspective}

International ethical guidelines suggest that hysterectomy is not an appropriate decision to cope with menstrual hygiene issues for intellectually disable females ${ }^{15}$. Globally, performance of non-therapeutic hysterectomy to cope with menstrual hygiene is a common issue. The laws, cultural, social norms and beliefs regarding such non-therapeutic procedures vary globally. In developed countries like Australia and the United Kingdom, hysterectomy for menstrual hygiene can only be performed with court authorization even if the family is in favour of hysterectomy ${ }^{9}$. But in developing and low middleincome countries including South Africa and India ${ }^{9}$ ${ }^{16}$, the court is not involved, and hysterectomy can be performed to address the issue of menstrual hygiene and sexual exploitation among ID individuals. In Jordan, around 64 to 70 nontherapeutic hysterectomies are performed annually to cope with menstrual hygiene ${ }^{17}$, while in Taiwan, surgical procedures for menstrual suppression are not approved ${ }^{18}$.

As far as the Muslim world is concerned, the Islamic scholars joined and signed the Article "convention on rights of persons with disabilities" in 2012. It states, "There is no provision in the law that permits or authorizes such operations, and it is not permissible to cause any harm to a person without any medical justification ${ }^{17}$. Moreover, a legal 
pronouncement (fatwa) was issued by the Council of Fatwa and Research and Studies that states, "It is forbidden in Islam that girls with intellectual disabilities undergo hysterectomies without any medical indication due to risks and negative effects of operation"17. Moreover, in the Islamic context, "Women should be treated in the same way when she is on her period as when she is not. We need to understand that menstruation is a natural phenomenon. If periods were a thing to be ashamed of, why would God give women periods?"19.

\section{Author's Position \& its justification}

After interpreting this case in the light of ethical principles and keeping in view the global and Islamic aspects, I (Author) realized that it is challenging to make reasonable decisions under such circumstances. Hence, in my opinion, the surgery should not be performed for the sake of mother interest. As it is undue harm to the sufferer that could develop a complication later, rather, alternative options other than surgery must be considered. Medication inhibiting mensuration could be used after consulting a physician. ID individuals and their families or caretakers should be indulged in the training and counselling sessions regarding menstruation associated issues. There is no doubt that it is a very challenging situation for the caregivers and other family members, but the individual rights cannot be superseded by the interest of the caretakers. However, any decision that violates or could potentially violate a human's fundamental right should be avoided or at least thought twice before reaching out to any decision that might be unjust for the sufferer.

However, the consequences of hysterectomy among females with intellectual disabilities are bidirectional. The surgery might save the daughter from the menstrual distress and hygiene problems. Other than that, the mother and other family members would no longer be stressed. But, if in case the surgical procedure is performed, it is as undue harm to the ID female and would be labelled as a violation of the female's rights and might lead to surgical complications. Moreover, the surgical expense and treatment costs increase the financial burden on the family. Therefore, it is essential to analyze all the aspects and configure a wise unbiased approach that preserves the rights of both the sufferer and the caretakers.

\section{Conclusion}

As a health care professional, it is very difficult to deal with such painstaking cases in the routine practice. In light of ethics, every aspect of the decision-making process has its value in these situations. There are no clearly defined criteria to decide in such a critical condition; however, by analyzing risk-benefit ratio and situation analysis, decisions can be made for the good of humanity.

\section{Recommendations}

Based on the interpretation of this case from every possible aspect and its consequences, we all must be well-aware of the surgery risks and complications. Health care policies should be established in order to ease the health care professionals for providing better and wise advice with respect to the medical situations and patient condition. Every health care setting should have a record-keeping system to identify the number of cases and utilize the recorded data in policy development. Furthermore, moral and psychological support programs should be started for the families of such individuals to help them in overcoming these stressful conditions.

\section{Conflicts of Interest}

None.

\section{Acknowledgement}

The author would like to acknowledge Dr. Rozina Karmaliani and Dr. Robyna Khan for their guidance and support for completion of this paper.

\section{Disclosure}

The idea behind writing the manuscript was driven from the case that I (Author) had gone through during nursing practice. The patient's mother was 
well-informed, and she provided consent for inclusion of the mentioned details.

\section{Funding}

None.

\section{References}

1. World Health Organization. World Report on Disability. Geneva, Switzerland: WHO Press; 2011. Available at: http://www.who.int/disabilities/world_report/2011/r eport.pdf

2. Márquez-González H, Valdez-Martinez E, Bedolla M. Hysterectomy for the management of menstrual hygiene in women with intellectual disability. A systematic review focusing on standards and ethical considerations for developing countries. Front Public Health. 2018;6:338.

3. Dare T. Parental rights and medical decisions. Paediatr Anaesth. 2009; 19:947-952.

4. Diekema DS, Fost N. Ashley revisited: a response to the critics. Am J Bioeth. 2010;10:30-44.

5. Roy A, Roy A, Roy M. The human rights of women with intellectual disability. J R Soc Med. 2012;105:384-389.

6. Swango-Wilson A. Caregiver perceptions and implications for sex education for individuals with intellectual and developmental disabilities. Sex Disabil. 2008;26(3):167.

7. Isler A, Beytut D, Tas F, Conk Z. A study on sexuality with the parents of adolescents with intellectual disability. Sex Disabil. 2009;27(4):229.

8. Park HR. Menstrual Support for Females with Developmental Disabilities: Survey and Interview of Parents or Caretakers (Doctoral dissertation, University of Kansas).

9. Roy A, Roy A, Roy M. The human rights of women with intellectual disability. J R Soc Med. 2012; 105(9):384-389.

10. Williams, K. The secrets of successful coaches. UK: Troubador Publishing; 2011: 1-89.

11. Beauchamp TL, Childress JF. Principles of biomedical ethics. USA: Oxford University Press; 2001.

12. Burkhardt $M$, Nathaniel $A$. Ethics and issues in contemporary nursing. Nelson Education; 2013.

13. Diekema DS, Fost N. Ashley revisited: a response to the critics. Am. J. Bioeth. 2010; 10(1):30-44.
14. Christman J. Relational autonomy and the social dynamics of Paternalism. Ethical Theory Moral Pract. 2014; 17(3):369-382.

15. Hod M, Kapur A, Sacks DA, Hadar E, Agarwal M, Di Renzo GC, Roura LC, McIntyre HD, Morris JL, Divakar $\mathrm{H}$. The International Federation of Gynecology and Obstetrics (FIGO) Initiative on gestational diabetes mellitus: A pragmatic guide for diagnosis, management, and care. Int J Gynecol Obstet. 2015;131:S173-211.

16. Medical Council of India on hystectomy in the mentally retarded [Letter]. Natl Med J India (1997) 10:36.

17. ALazzeh M. Civil Society Report on the Status of Implementation of the Convention on the Rights of Persons with Disabilities in Jordan "Mirror of Reality and a Tool for Change" (Internet). 2018.

18. Chou YCh, Zxy-Yann JL, Frank TYW, Chang-Fu L, LiChan L. Meanings and experiences of menstruation: perceptions of institutionalized women with an intellectual disability. J Appl Res in Intellect Disab. 2008; 21:575-584.

19. AlBustanji M, Bdour N, Beirat M. Hysterectomy of girls with intellectual disabilities in Jordan: a family perspective. IJLD. 2018; 8(1):53-72. 